enquiries into the prevalence of trachoma in the U.S. Navy during recent years, and has published (The News Letter, October, 1917) the following figures submitted by Surgeon-General W. C. Braisted, of the American Navy :-

$\begin{array}{ccccc}\text { Year. } & & \begin{array}{c}\text { Strength of Navy } \\ \text { and Marine Corps. }\end{array} & & \begin{array}{c}\text { Cases of } \\ \text { Trachoma. }\end{array} \\ 1912 & \ldots & 61,897 & \ldots & 3 \\ 1913 & \ldots & 65,926 & \ldots & 8 \\ 1914 & \ldots & 67,141 & \ldots & 8 \\ 1915 & \ldots & 68,075 & \ldots & 31 \\ 1916 & \ldots & 69,294 & \ldots & 12 \\ & & & \end{array}$

\title{
American Ophthalmology and the War
}

Major James Bordley, chairman of the sub-committee of ophthalmology of the Council of National Defence, recently outlined to the Clinical Congress of Surgeons of North America, the more important steps taken by his sub-committee with regard to ophthalmology in war. These form interesting reading to the Allies. The sub-committee includes Majors G. E. de Schweinitz, Nelson Miles Black, W. H. Wilmer, Walter R. Parker, and Allen Greenwood. A complete and classified catalogue of all ophthalmologists in America was prepared, and the names of 1,400 men willing and qualified to serve were handed to the Surgeon-General. Of this number more than 300 have been commissioned and upwards of 200 ordered on active duty. The sub-committee has studied the SurgeonGeneral's plans for the organization of the army hospitals, and, where requested, has made suggestions as to the staff and equipment necessary for eye work. A small book has been written ("Ophthalmic Military Surgery, with chapters on Trachoma and Malingering.") The visual requirements for various services of the Army have been considered. The sub-committee of ophthalmology has suggested a glass which possesses a selective absorption of light waves for use in binoculars, field glasses, and range-finders. It has caused to be made for the first time in the United States the soda glass necessary in the manufacture of artificial eyes, heretofore obtained exclusively from Germany. A member of Major Bordley's subcommittee has devised a plan for protecting eyes against injury, believed to be of far-reaching value. The re-education of blind soldiers has not been overlooked. Twelve of the leading authorities on the blind have been called together, so that this complex question may be fully considered. In order to assist the work a patriotic lady has placed her country estate at the disposal of the SurgeonGeneral. Soldiers blinded in the war will be retained in the military service until they have been trained and placed in a suitable trade or profession. Lastly, ophthalmology is to be grouped with 
brain surgery, the plastic surgery of the face, and oto-laryngology into a department on "Surgery of the Head."

An account of Major Bordley's remarks will be found in the December number of our contemporary, Surgery, Gynecology, and Obstetrics (p. 727).

\section{ABSTRACTS}

\section{I.-THE CANAL OF SCHLEMM}

Maggiore, L. (Rome). - The structure, behaviour, and significance of the canal of Schlemm in the human eye in normal and pathological states. (Struttura, comportamento e significatio del canale di Schlemm nell 'occhio umano in condizioni normali e patologiche.) Annal. di Ottal. e Clin. Ocul., May-June, 1917.

Maggiore gives an account of his investigations into the anatomy of the canal of Schlemm. His methods included the injection of coloured masses by the arterial trunks, the examination of serial microscopic sections and the plastic reconstruction of such sections in the method used by embryologists. As a result he states that:1. The canal of Schlemm in man, from the morphological standpoint, is evidently a vascular structure. 2. The canal is joined to a closed vascular plexus (deep peri-corneal plexus) formed of numerous veins, with a few slender and scanty arterial twigs. 3. The connections between that plexus and the canal are formed by a small number of collecting trunks, about 20 to 30 , with very small lumen, and even when filled with red blood corpuscles, they only appear as slits. 4. There are no preformed spaces round the canal or the collecting trunks.

He made further experiments on a possible connection of the canal with the anterior chamber and was able to satisfy himself that no such connection existed, and that the canal had a complete endothelial lining. He also found that under normal conditions the canal contains only lymph and not red blood corpuscles, although these latter may easily be forced into it under conditions of pressure. He made some examinations of the eyes of animals, especially those likely to be used for experimental work, and found it necessary to draw a distinction between the canal and the spaces of Fontana, as the one may exist without the other. In man the only evidence of a canal of Fontana is to be found in the seventh month of foetal life and disappears at birth. The ape, whose eye most resembles the human one, possesses a canal of Schlemm exactly similar, but, 